\title{
EFEITO DA INFORMAÇÃO NA SIMULAÇÃO DE UM LEILÃO DE PREÇO RESERVA
}

\section{1- Bruno Vinícius Ramos Fernandes \\ Universidade de Brasília - UnB \\ brunoramos@unb.br}

\section{3- César Augusto Tibúrcio Silva \\ Universidade de Brasília - UnB \\ cesaraugustotiburciosilva@gmail.com}

\author{
2- Josué Lins Silva \\ Universidade Federal do Rio Grande do Norte - UFRGN \\ josue.lins@uol.com.br
}

\section{Diego Maganhotto Coraiola - Editor}

\section{RESUMO}

Este trabalho buscou evidenciar se a inclusão de informações sobre produtos altera substancialmente as estimativas de preços dos produtos na simulação de leilões de preço reserva. Os produtos escolhidos foram: mouse, tênis, relógio e o wice que é um refrigerador de bebidas desconhecido no mercado brasileiro. Foi testado também se uma âncora aleatória pode influenciar nas estimativas de preços, a âncora escolhida foi os três últimos dígitos da Identidade de cada participante. Como resultado encontrou-se que âncora afeta as estimativas de preços dos quatro produtos quando leiloados sem informação. A inclusão da informação aumentou significativamente os preços ofertados e diminuiu o efeito da âncora aleatória. Nos quatro produtos pesquisados ocorreu a Maldição do Vencedor, tanto nos leilões com informação quanto nos leilões sem informação.

\section{Palavras-Chave}

Leilão de preço reserva, maldição do vencedor, âncora aleatória.

\section{ABSTRACT}

This study sought evidence if the inclusion of information on products substantially alter the estimates of prices in the simulation of the auction reserve price. The products chosen were: mouse, shoes, watch and wice which is a cooler of drinks don't known in the Brazilian market. It also tested a random anchor can influence the estimates of prices, was chosen to anchor the last three digits of the identity of each participant. As a result it was found that anchor affects the estimates of prices when auctioned four products without information. The inclusion of the information offered increased prices and decreased the effect of random anchor. Four products were investigated in the Winner's Curse occurs, both in auctions with and without information.

\section{Keywords}

Auction reserve price, winner's curse, random anchor. 


\section{Introdução}

Este estudo trata de um experimento que consistiu na simulação de um leilão, a fim de verificar a influência de uma âncora aleatória de preços na estimativa de valores dos leilões e também analisar se o efeito na informação diminui o impacto da Maldição do Vencedor.

Os leilões de acordo com Varian (2006, p. 334) "constituem uma das mais antigas formas de mercado, remontando, pelo menos, ao ano 500 a.C.".

De acordo com Varian (2006, p. 335-336) há quatro tipos de leilões:

1. Leilão inglês: o leiloeiro parte de um preço reserva que é o menor preço pelo qual o vendedor se desfará do bem;

2. Leilão holandês: o leiloeiro inicia com um preço alto e o reduz gradualmente até que alguém o adquira. Na prática, o "leiloeiro" é um instrumento mecânico;

3. Leilão de lance fechado: cada um dos participantes escreve seu lance em um pedaço de papel e o coloca em um envelope fechado. Esses envelopes são reunidos e o bem cabe a quem apresentou o maior lance;

4. Leilão filatelista ou leilão de Vickrey: a primeira denominação decorre do fato de que este lance era utilizado originalmente por colecionadores de selo; a segunda é uma homenagem a Wiliam Vickrey, ganhador do Nobel de 1996 por seu pioneiro trabalho na análise de leilões. O leilão de Vickrey se distingue do leilão de lance fechado em um aspecto crítico: o bem cabe a quem apresenta o lance mais elevado. Em outras palavras, quem oferece mais fica com o bem, mas paga o preço oferecido por quem fez o segundo lance mais alto.

Conforme Varian (2006, p. 115), o leilão do tipo preço reserva, diz o seguinte:

\begin{abstract}
O termo preço de reserva vem do mercado de leilões. Quando alguém queria vender algo em leilão, essa pessoa em geral estabelecia um preço mínimo pelo qual estava disposta a vender o bem. Se o melhor preço oferecido estivesse abaixo do preço declarado, o vendedor reservava-se o direito de comprar o item ele mesmo. Esse preço passou a ser conhecido como preço de reserva do vendedor e acabou por ser usado para descrever o preço pelo qual alguém está exatamente disposto a comprar ou vender alguma coisa.
\end{abstract}

Para fundamentar esse trabalho, buscou-se informações em estudos de Ariely (2008), que dizem que a algumas décadas, o naturalista Konrad Lorenz descobriu que os gansinhos, quando saem do ovo, se apegam à primeira coisa em movimento que encontram (que, em geral, é mãe). Com base nessa observação de Lorenz, Ariely busca identificar em seus experimentos se o cérebro humano também é programado igual ao dos gansos.

Em seu experimento, Ariely (2008, p. 21) faz o seguinte:

Se eu lhe pedisse os dois últimos dígitos do seguro social (os meus são 79), depois perguntasse se você pagaria esse número em dinheiro (no meu caso seria $\mathrm{R}$ \$ 79) por determinada garrafa de Côtes Du Rhône 1998, a mera sugestão desse número influiria no quanto você estaria disposto a pagar por um vinho? Parece absurdo, não é? Então espere até vir o que aconteceu com um grupo de alunos de MBA do MIT há alguns anos.

A experiência de Ariely (2008) consistiu na distribuição de uma lista contendo os produtos a serem leiloados. Em seguida foi solicitado que cada um colocasse os dois últimos números do seguro social e respondesse se pagaria ou não esse valor pelos objetos e, após, qual o valor máximo que estaria disposto a pagar. Ao final do experimento foi observado que os alunos com dígitos verificadores do seguro social maiores (80 a 99) fizeram os lances mais altos e, os que tinham dígitos menores (1 a 20) fizeram os lances mais baixos.

Outro ponto observado no experimento foi a incidência do fenômeno Winner's Curse que se traduz como a Maldição do Vencedor. Esse fenômeno acontece quando os valores pagos por determinado ativo são superiores ao real.

Segundo Silva (2007), Winner's Curse, ou Vitória de Pirro, como também é conhecida, pode ser assim conceituada:

\begin{abstract}
"(...) é uma situação onde o ganhador é na realidade o grande perdedor. Uma situação típica da Vitória de Pirro ocorre em leilão. O ganhador de um leilão é aquele que deu o maior lance e provavelmente tem maiores expectativas do valor de um bem. Essas expectativas estão, no entanto, acima do padrão normal das pessoas. Ou seja, a pessoa paga mais do que deveria nessa situação".
\end{abstract}

Quanto ao fenômeno da Maldição do Vencedor, Thaler (1988) apud Vanzan (2004, p. 4) diz que "a ocorrência da maldição do vencedor pode representar um desafio ao paradigma econômico. Isso por que "a maldição do vencedor não pode ocorrer se todos os participantes forem racionais $[\ldots] "$.

Ainda, Vanzan (2004, p. 4-5), relata:

Cox e Isaac (1984) mostram que agentes que maximizam a utilidade esperada revêem suas estimativas para baixo e reduzem suas ofertas de modo a não incorrerem na maldição do vencedor (KAGEL et al, 1989). Cox e Isaac (1984, p.579, tradução nossa) concluem que se a maldição do 
vencedor é uma realidade comportamental, então os participantes de leilão não estão em geral utilizando estratégias ex ante ótimas. Nas palavras de Kagel e Levin (1986, p.894, tradução nossa), a ocorrência da maldição do vencedor "implica que os participantes de leilão errem repetidamente, violando noções básicas de racionalidade econômica. Por isso, a existência do fenômeno representa um desafio ao padrão de comportamento dos agentes econômicos usualmente aceito.

Vários fatores causam a Maldição do Vencedor. Segundo Vanzan (2004), basicamente há dois problemas associados: o primeiro diz respeito ao grau de incerteza sobre o valor do bem a ser leiloado e o segundo que foi identificado por Bazerman e Samuelson (1983) diz respeito ao número de participantes de um leilão, já que quanto maior o número de participantes maior seria a variância das estimativas e das ofertas.

Vanzan (2004) diz ainda que esse fenômeno foi observado na indústria do petróleo, já que as companhias petrolíferas avaliaram suas aquisições em leilões de áreas leiloadas pelo governo americano na década de 60 . Foi observado que a oferta vencedora excedeu a segunda por um fator igual a quatro em $26 \%$ das concessões e um fator igual a dois em $77 \%$. Esses erros de estimativa é que fazem surgir o fenômeno da Maldição do Vencedor e, foi o causador da baixa rentabilidade das companhias petrolíferas.

Em estudo recente Brasil, Postali e Madeira (2008), sobre assimetrias entre competidores nos leilões de petróleo no Brasil, chegaram às conclusões preliminares de que nos leilões efetuados no período de 1999 a 2007, há indícios de assimetria, já que os lances oferecidos pela Petrobrás foram maiores que os demais concorrentes. Esses valores a maior, conclui os autores, podem estar associados a um know-how em relação aos demais concorrentes.

No Brasil, o tipo de leilão utilizado para os lotes de áreas de exploração de petróleo é um sistema de leilão selado de primeiro preço. Mattos (2008, p. 71) descreve que:

Em um sistema de leilão selado de primeiro preço não há essa oportunidade de aprendizado. Só há um round de ofertas e mesmo conhecendo todos os lances dados, não há qualquer chance de revisão: o leilão tem vencedor definitivo. Cada player, incapaz de observar os lances de outros player, e aprender mais sobre o verdadeiro valor do objeto, tenderá a ser o mais precavido possível, temeroso de que possa estar fazendo lances baseados em suas expectativas individuais, que acabem se revelando excessivamente otimistas.

Considerando que o experimento foi aplicado em dois grupos diferentes, sendo um com informação e outro sem informação, buscou-se identificar se o efeito da informação sobre os produtos (marca, descrição, utilidade, etc.) influencia na Maldição do Vencedor, já que com informação, os lances tenderiam a ficar mais próximos do valor justo. Além disso, buscou-se identificar quais variáveis afetaram as estimativas de preços e se a âncora influencia nos lances ofertados aos produtos.

Desta forma, foram traçados os objetivos do trabalho, que são os seguintes:

1. Verificar se uma âncora aleatória de preços se correlaciona com as estimativas de valores.

2. Verificar se o efeito informação diminuiu a Maldição do Vencedor.

3. Verificar se há diferenças entre as médias dos lances, nos leilões com informação e sem informação.

As hipóteses a serem testadas, foram construídas com base nos objetivos acima descritos e são citadas abaixo:

$\mathrm{H}_{1}$ : Há correlação positiva entre a âncora aleatória de preços e as estimativas de valores.

$\mathrm{H}_{2}$ : $\mathrm{O}$ aumento do nível informacional nos leilões diminuiu a Maldição do Vencedor.

$\mathrm{H}_{3}$ : A média dos lances nos leilões com informação é maior do que a do leilão sem informação.

\section{Metodologia}

\subsection{Simulações de leilões de preço reserva}

O experimento foi efetuado em dois grupos distintos: um com informação sobre o produto e o segundo grupo sem informação, aplicados na cidade de Natal (Universidade Federal do Rio Grande do Norte - UFRN e Universidade Potiguar UnP) e Brasília (Centro Universitário - UNIEURO).

Foram projetados no datashow os produtos, depois foi explicada a forma de preenchimento e o incentivo. Os dados censitários foram preenchidos no cabeçalho, depois os participantes colocaram os três últimos números da identidade ao lado de cada produto. Foi informado também que cada um que participasse do leilão, receberia como brinde um pequeno chocolate. Os lances que mais se aproximassem do valor de mercado, receberiam uma caixa de chocolate. 
Após recolhido os questionários com os lances, foi tabulado em planilha de Excel e verificado quais os lances que ficaram mais próximos dos valores de mercado a fim de apurar os lances merecedores do incentivo maior, que era a caixa de chocolate.

Os questionários continham quatro produtos: mouse, tênis, relógio e produto para conservar vinho (wice). No primeiro, sem informação, havia apenas a fotografia dos produtos sem as marcas e, ao lado de cada fotografia as perguntas. No segundo questionário, além dos dados do primeiro, as fotografias dos produtos estavam acompanhadas das respectivas marcas.

Durante a aplicação dos questionários, foi observado a influência da marca dos produtos, já que no grupo sem informação, grande número de pessoas solicitou informações das marcas, a fim de ter parâmetro de preço. Essas indagações não foram respondidas, alegando que a marca não seria informada e que os preços deveriam ser atribuídos de acordo com a fotografia dos produtos.

\subsection{Análise da Amostra}

A simulação do leilão foi feita em Brasília-DF e Natal-RN. A pesquisa foi aplicada em uma universidade pública e duas particulares. Na capital federal foram 45 questionários com informação e 52 sem informação, já na capital potiguar obtiveram-se 50 questionários com informação e 63 sem informação. Por não ter havido evidência significante de diferença censitária da amostra entre os dois estados, os dados foram agrupados em "com informação" e "sem informação" e analisados desta forma.

\subsubsection{Leilão com informações sobre os produtos}

No questionário com informações foram expostas as marcas dos produtos com seus respectivos logotipos e instruções sobre as funcionalidades do bem objeto de avaliação.

No total participaram do leilão com informação 95 pessoas, em torno de $42 \%$ de mulheres e $58 \%$ de homens.

Quanto ao estado civil, os participantes tinham quatro opções: solteiro, casado, divorciado e outros. A grande maioria, 77\%, declararam-se solteiros, cerca de $15 \%$ casados, $5 \%$ outros e $2 \%$ divorciados, uma pessoa não respondeu a questão.
A distribuição de idades, demonstra que a grande maioria dos participantes da simulação do leilão, cerca de 83\% possuem idade entre 19 e 30, sendo que só na faixa de 19 à 22 anos estão mais de $58 \%$ da amostra.

\subsubsection{Leilão sem informações sobre os produtos}

No leilão sem informações, a distribuição da amostra quanto ao gênero está bem dividida. Observa-se que cerca de $49 \%$ dos participantes são mulheres e 51\% homens. Dois questionários foram descartados pelo fato de as variáveis censitárias não terem resposta. Sendo assim, do total de 115, foram válidos para análise 113.

Analisando o estado civil, $60 \%$ dos participantes se declararam solteiros, $36 \%$ casados e os restantes estão divididos entre divorciados e outros que são a minoria.

Para a distribuição de idades, 78\% da amostra encontra-se no intervalo de 18 a 33 anos de idades. Isto explica por que a maioria dos participantes são solteiros, em função da tenra idade que predomina.

De forma geral, em relação aos dados censitários, as duas amostras selecionadas, com e sem informação, estão bem próximas, não há grandes diferenças quanto ao gênero, estado civil e idade.

\section{Análise de Resultados}

\subsection{Estatísticas descritivas: questionário com informação}

Como um dos objetivos do trabalho foi verificar a influência da âncora de preços na atribuição de valor aos produtos na simulação de um leilão de preço reserva, foi feita a pergunta ao lado de cada produto: "você pagaria o valor dos três últimos números de sua identidade por esse produto?". Esta é uma tentativa de associação para se formar a âncora, pois a idéia é que independente da resposta ser afirmativa ou negativa crie-se um vínculo entre os três últimos números da identidade e o preço ofertado ao produto. A seguir é apresentado o Quadro 1, onde a intenção é demonstrada. 
Quadro 1 - Intenção de pagar ou não os três últimos dígitos da identidade

\begin{tabular}{|l|c|c|}
\hline Identidade & Paga & Não Paga \\
\hline Mouse & $8 \%$ & $92 \%$ \\
Tênis & $43 \%$ & $57 \%$ \\
Relógio & $56 \%$ & $44 \%$ \\
Wice & $20 \%$ & $80 \%$ \\
\hline
\end{tabular}

O produto mouse possui uma amplitude de preço relativamente grande no mercado. Em rápida busca na internet em um site especializado, foram encontrados preços que variam de $R \$ 9,90$ à $R \$$ 299,90. Como geralmente as pessoas associam este produto como sendo de baixo custo, em virtude dos demais preços de produtos na área de informática, e a âncora de preços que leva em consideração os três últimos números da Identidade, podendo variar de 000 a 999, quem possuía os três últimos números a partir de 100, considerou um valor alto para ser pago ao produto, sendo assim, a grande maioria 92\% respondeu que não pagaria o valor referente à âncora ao referido produto. O mesmo aconteceu com o wice, que por ser um produto desconhecido no mercado e de aparência simples, não parecendo ter um alto custo de produção, a grande maioria $80 \%$ não aceitou pagar a âncora pelo produto.

Quadro 2 - Estatísticas descritivas do leilão com informação

\begin{tabular}{|l|r|r|r|r|}
\hline \multicolumn{1}{|c|}{ Estatísticas } & \multicolumn{1}{c|}{ Mouse } & \multicolumn{1}{c|}{ Tênis } & \multicolumn{1}{c|}{ Relógio } & \multicolumn{1}{c|}{ Wice } \\
\hline Média & 90,56 & 377,96 & 606,87 & 243,43 \\
Mediana & 78,00 & 360,00 & 500,00 & 150,00 \\
Máximo & 700,00 & 990,00 & 2999,00 & 2000,00 \\
Mínimo & 9,00 & 80,00 & 80,00 & 14,90 \\
Desvio Padrão & 91,07 & 177,59 & 502,99 & 326,77 \\
Coef. de Variação & $101 \%$ & $47 \%$ & $83 \%$ & $134 \%$ \\
\hline
\end{tabular}

Pode-se visualizar melhor esta relação no Quadro 2 acima, onde as médias dos lances ofertados pelo mouse e pelo wice, foram as menores dos quatro produtos analisados, e os coeficientes de variação foram os dois maiores, apresentando alta dispersão na amostra. É interessante notar que o produto wice, foi o que demonstrou maior dispersão nas estimativas, com coeficiente de variação de $134 \%$, como o produto é desconhecido no mercado aumenta a incerteza sobre seu valor. Quanto aos produtos tênis e relógio a intenção de pagar ou não a âncora de preços está bem dividida. Em torno de 43\% tomaram a decisão de pagar e $57 \%$ de não pagar a âncora de preços para o tênis, já o relógio $56 \%$ dizem pagar e 44\% não pagam os três últimos dígitos da Identidade no respectivo produto.

\subsection{Estatísticas descritivas: questionário sem informação}

No questionário sem informação, em relação aos quatro produtos, a maioria das pessoas respondeu que não pagaria a identidade em valor. Os percentuais são semelhantes às respostas do com informação, mas nota-se que neste a quantidade de pessoas que aceitam pagar a âncora aleatória é um pouco maior, evidenciando o efeito da informação nas tomadas de decisões.
Quadro 3 - Intenção de pagar ou não os três últimos dígitos da identidade

\begin{tabular}{|l|c|c|}
\hline Produto & Paga & Não Paga \\
\hline Mouse & $11 \%$ & $89 \%$ \\
Tênis & $27 \%$ & $73 \%$ \\
Relógio & $43 \%$ & $57 \%$ \\
Wice & $12 \%$ & $88 \%$ \\
\hline
\end{tabular}

Comparando as estatísticas descritivas, percebe-se que as medidas de tendência central média e mediana do questionário com informação são todas maiores do que as do sem informação. Fica claro que o efeito informacional, principalmente o quesito marca, afetou a atribuição de valor dos produtos, isso era esperado e é mais uma prova da importância da criação deste intangível para as empresas. O produto wice, que a princípio seria imune do efeito marca, também foi fortemente influenciado. Enquanto a média de preços do Quadro 4 para este produto foi de $\mathrm{R} \$$ 97,27 ; observa-se que no questionário com informação foi superior 2,5 vezes, com preço estimado R\$243,43. A simples inclusão do logotipo do produto, apesar de desconhecido, fez com que os lances ofertados fossem significativamente maiores. 
Quadro 4 - Estatísticas descritivas do leilão sem informação

\begin{tabular}{|l|r|r|r|r|}
\hline \multicolumn{1}{|c|}{ Estatísticas } & Mouse & \multicolumn{1}{c|}{ Tênis } & Relógio & \multicolumn{1}{c|}{ Wice } \\
\hline Média & 54,69 & 231,03 & 298,88 & 97,27 \\
Mediana & 38,50 & 199,90 & 250,00 & 70,00 \\
Máximo & 700,00 & 900,00 & 1000,00 & 800,00 \\
Mínimo & 9,00 & 35,50 & 18,00 & 12,00 \\
Desvio Padrão & 74,41 & 151,14 & 211,49 & 107,85 \\
Coef. De Variação & $136 \%$ & $65 \%$ & $71 \%$ & $111 \%$ \\
\hline
\end{tabular}

A diferença nas estimativas também pode ser evidenciada quando analisados os pontos de máximo e de mínimo. Nos questionários com informação estes extremos são maiores em três dos quatro produtos: tênis, relógio e wice. Para o produto mouse, coincidentemente os pontos de máximo e mínimo são exatamente iguais, mas as medidas de tendência central são sempre maiores no questionário com informação.

Com relação à dispersão, não foi encontrado diferença significativa entre os questionários com e sem informação. Os dois apresentaram alta variabilidade por possuírem coeficiente de variação maior que $30 \%$. Pode-se inferir que, independente de existir informação, as estimativas de preços tendem a ser heterogêneas, talvez influenciadas por vieses cognitivos inerentes a cada pessoa, além do que, pode ser que, alguns estejam mais familiarizados com determinados produtos do que outros. Em relação aos vieses cognitivos, um dos mais significativos neste estudo, são as tendências que algumas pessoas podem ter em subestimar ou superestimar preços. Desta forma, foi dado um tratamento especial a estes casos como descrito a seguir.

\subsection{Efeitos de subestimação e superestimação de preços}

No decorrer dos testes verificou-se que tinham pessoas que tendiam a aumentar os preços e outras a baixar os mesmos. Para analisar tal fato, foi utilizada a função "ordem percentual" do Microsoft Excel ${ }^{\circledR}$, que retorna a ordem percentual de um valor em um conjunto de dados como um percentual do conjunto de dados. Esta função pode ser usada para avaliar a posição relativa de um valor em um conjunto de dados. Sendo assim quanto mais próximo de um, o preço ofertado pelo produto estiver, mais a pessoa tende a pagar alto por ele, como são quatro produtos, na soma da ordem percentual, o que se aproximar de quatro é aquele que tende a pagar um preço mais alto para todos os produtos.

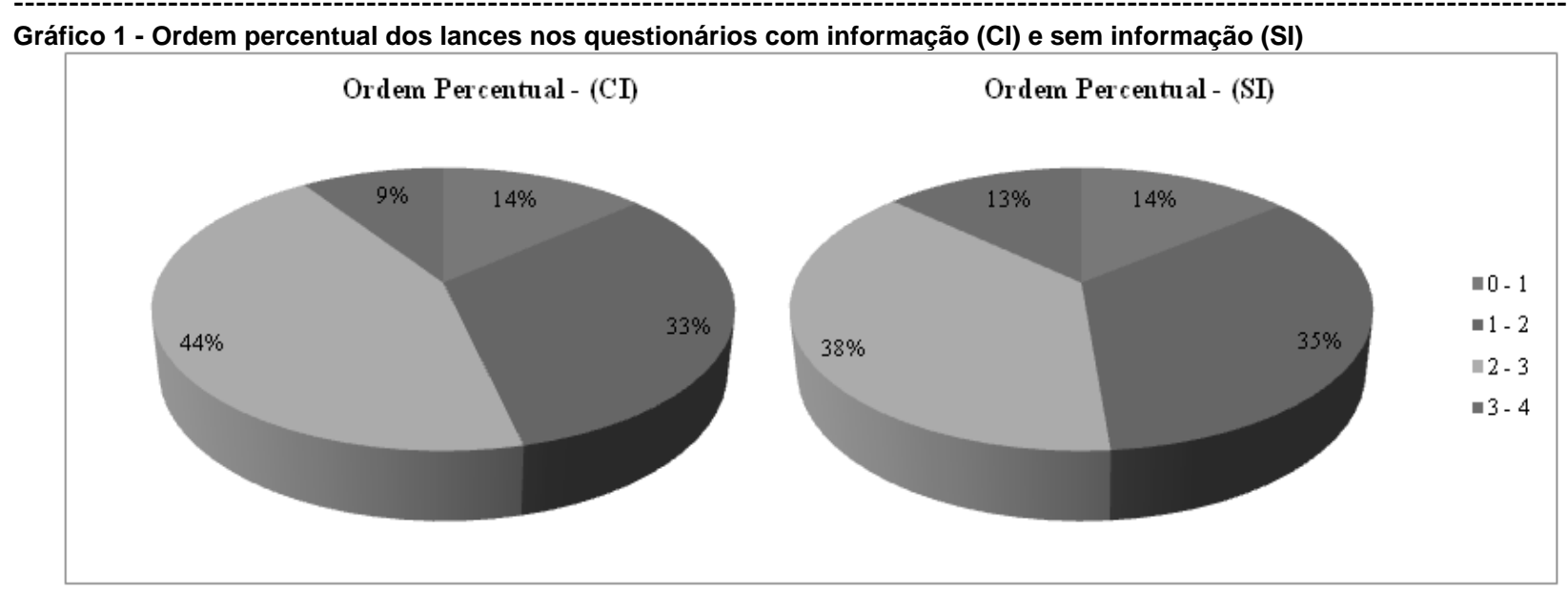

O gráfico 1 foi construído em quatro intervalos, estes estão divididos de acordo com a soma das ordens percentuais, sendo assim, os dados que possuem ordens percentuais de soma de 0 a 1 , correspondem a $14 \%$ do total, tanto para $\mathrm{Cl}$ quanto para SI, estas pessoas tendem a subestimar os preços dos produtos. Os intervalos de 1 a 2 e de 2 a 3, correspondem a maioria das somas das ordens percentuais, juntos correspondem a $77 \%$ para $\mathrm{Cl}$ e $73 \%$ para $\mathrm{SI}$, estas pessoas são medianas na 
oferta de preço, ou seja, sem tendência de alta ou de baixa. No intervalo de 3 a 4 estão aqueles que superestimam os valores, correspondem a $9 \%(\mathrm{Cl})$ e $13 \%(\mathrm{SI})$.

Este fato pode ter "atrapalhado" a influência da âncora aleatória, visto que, as pessoas com tendência já definida de estimação de preços, subestimar ou superestimar, devem estar menos suscetíveis a âncora aleatória do que pessoas sem tendência definida, as aqui chamadas de medianas.

Em função deste viés, de sub ou superestimação, foram consideradas nos modelos de regressão linear, duas variáveis Dummy, uma chamada $D_{\text {maior }}$ que representa aquelas pessoas com ordem percentual entre 3 e 4 e outra intitulada $D_{\text {menor }}$ sendo aquelas que possuem ordem percentual entre 0 e 1 . O objetivo da inserção destas variáveis Dummy no modelo, foi tentar capturar estes efeitos de sub e superestimação, verificando sua significância e influência nas estimações. Além disso, é esperado que ao retirar este efeito, a âncora aleatória seja significante nas estimativas preços, pois a tendência de alta ou de baixa nos preços sendo eliminada a âncora teria total "liberdade" para agir nas estimativas.

\subsection{Resultados das regressões lineares}

\subsubsection{Amostra completa}

A regressão linear é uma técnica estatística que busca encontrar alguma relação de causalidade entre as variáveis. Com este objetivo foram rodadas regressões, tentando encontrar algumas relações entre as variáveis deste estudo. Os dados utilizados num primeiro momento não foram segregados, ou seja, estão juntos tanto o questionário com informação quanto 0 sem informação. Neste caso, a informação foi inserida no modelo com uma variável Dummy, onde ficou zero quando não se tinha informação e um quando se tinha. Também foram incluídas como variáveis independentes as variáveis censitárias: sexo $^{1}$, idade, estado civil $^{2}$ e localidade ${ }^{3}$. Abaixo são descritos os modelos de regressão linear ${ }^{4}$ :

$$
\begin{aligned}
& P_{\text {mouse }}= \\
& \propto+0,515 D_{\text {maior }}-0,162 D_{\text {menor }}+0,218 I_{p} \\
& -0,088 G E N \\
& \begin{aligned}
P_{\text {tênis }}=\propto+0,31 & D_{\text {maior }}-0,285 D_{\text {menor }}+0,41 I_{p} \\
& +0,405 A N C+0,153 I N F \\
& +0,069 I D A
\end{aligned}
\end{aligned}
$$

$$
\begin{aligned}
& P_{\text {relógio }}=\propto+0,244 D_{\text {maior }}-0,165 D_{\text {menor }}+0,257 I_{p} \\
& +0,195 A N C+0,206 I N F \\
& +0,141 L
\end{aligned}
$$

Onde:

$P=$ Preço estimado de cada produto.

$D_{\text {maior }}=$ Variável dummy que representa as pessoas com soma de ordem percentual maior que quatro;

$D_{\text {menor }}=$ Variável dummy que representa as pessoas com soma de ordem percentual menor que um;

$I_{p}=$ Intenção de pagar a âncora aleatória (identidade) no produto $\mathrm{p}$;

$G E N=$ Gênero, masculino ou feminino;

$A N C=$ Âncora aleatória, três últimos dígitos da identidade;

$I N F=$ Informação sobre os produtos;

$I D A=$ Idade do participante em anos;

$L=$ Local, Brasília ou Natal.

As regressões foram estimadas no software estatístico SPSS (Statistical Package for the Social Sciences), pelo método stepwise, onde o programa roda o modelo com todas as variáveis e de acordo com os testes de significância são retiradas variáveis e testados outros modelos, de forma tal que, no modelo final todas as variáveis nele incluídas são significantes. As equações acima são os resultados finais, ou seja, todas estas variáveis independentes são significantes.

Foi encontrado que a informação é determinante nas estimativas de preços em três produtos: tênis, relógio e wice. A âncora aleatória (identidade) teve impacto nos preços do tênis, relógio e wice, sendo significante em $75 \%$ dos produtos. As variáveis Dummy que representam as tendências de elevar ou baixar preços foram significantes em todos os casos, exceto para o wice onde o $D_{\text {menor }}$ não foi significante ao nível máximo tolerado de $15 \%$. Quanto a estas variáveis pode-se inferir que o fato de existirem pessoas que se inclinam a aumentar ou diminuir preços é impactante nestas estimativas e estas sofrem menos efeitos das âncoras, pois quando não considerados estes fatores os modelos não mostraram respostas das estimativas aos três 
últimos dígitos da identidade. Antes que o participante escrevesse o preço máximo pago por determinado produto ele deveria sinalizar se pagaria ou não a âncora, esta variável foi considerada e descrita nas equações acima como $I_{p}$, em todos os preços estimados dos quatro produtos ela foi significante, ou seja, a resposta do participante em pagar ou não a âncora pelo produto foi determinante na estimativa que foi ofertada, isto demonstra certa coerência nas respostas e não um efeito totalmente aleatório que se esperava.

Quanto às variáveis censitárias, a idade foi significante em dois produtos, tênis e wice. Para o primeiro a relação foi positiva, ou seja, quanto maior a idade, maior era o preço atribuído ao produto, ou vice-versa, já para o segundo, o sinal foi negativo, quanto maior a idade menor o preço estimado, ou vice-versa. Para o mouse o gênero foi significante e com sinal negativo, demonstrando que os homens tendem a estimar preços menores para este produto do que as mulheres. O preço do relógio foi influenciado pela localidade, os participantes de Brasília tendem a pagar mais por este produto do que os de Natal.

\subsubsection{Amostra dos questionários sem informação}

Segregando os dados, de forma a ter duas amostras, uma sem e outra com informação, foram estimados os modelos de regressão linear de forma separada, assim foram testadas todas as variáveis independentes como anteriormente descrito, exceto a informação, visto que não se faz mais necessário, por terem sido separados os dados. Abaixo os resultados encontrados:

$$
\begin{aligned}
& P_{\text {mouse }}=\propto+0,372 D_{\text {maior }}-0,136 D_{\text {menor }}+0,312 I_{p}+0,208 A N C-0,209 L \\
& P_{\text {tênis }}=\propto+0,352 D_{\text {maior }}-0,235 D_{\text {menor }}+0,434 I_{p}+0,345 A N C \\
& P_{\text {relógio }}=\propto+0,258 D_{\text {maior }}-0,181 D_{\text {menor }}+0,420 I_{p}+0,397 A N C \\
& P_{\text {wice }}=\propto+0,322 D_{\text {maior }}-0,139 D_{\text {menor }}+0,423 I_{p}+0,154 A N C
\end{aligned}
$$

Agora, com a separação, os preços estimados dos quatro produtos nos questionários sem informação são afetados pela âncora, ou seja, houve influencia da identidade nas estimativas dos preços em $100 \%$ dos casos. A intenção de pagar ou não a âncora continua sendo significante em todos os casos e a localidade influenciou o preço do mouse, demonstrando que os participantes de Brasília tendem a pagar menos por este produto do que os de Natal.
Pode-se inferir de acordo com os resultados encontrados que, a falta de informação sobre os produtos fez com que as pessoas sofressem plena influencia da âncora aleatória.

\subsubsection{Amostra dos questionários com informação}

Estimando as regressões somente com os dados dos questionários com informação, obtiveram-se os seguintes resultados:

$$
\begin{gathered}
P_{\text {mouse }}=\propto+0,359 D_{\text {maior }}-0,135 D_{\text {menor }}+0,253 I_{p}+0,272 L \\
P_{\text {tênis }}=\propto+0,136 D_{\text {maior }}-0,236 D_{\text {menor }}+0,408 I_{p}+0,524 A N C+0,171 I D A \\
P_{\text {relógio }}=\propto-0,221 D_{\text {menor }}+0,301 I_{p}+0,171 A N C+0,314 L-0,185 E C \\
P_{\text {wice }}=\propto+0,221 D_{\text {maior }}-0,156 D_{\text {menor }}+0,427 I_{p}-0,189 I D A
\end{gathered}
$$

Onde:

$E C=$ Estado Civil, solteiro ou casado. 
Observa-se que a âncora surtiu efeito apenas nos produtos tênis e relógio, sendo assim, o efeito informacional diminuiu a influencia da âncora aleatória nas estimativas de preços, pois dois produtos não foram afetados por ela.

A variável localidade influenciou o preço do relógio e do mouse, mostrando que as pessoas de Brasília tendem a pagar mais por estes produtos do que as de Natal. O preço do wice foi afetado negativamente pela idade, ou seja, quanto maior a idade menor a estimativa de preço, ou vice-versa. A idade também afetou o preço do tênis de forma positiva. O preço do relógio foi influenciado pelo estado civil de forma negativa, os casados tendem a pagar menos pelo produto do que os solteiros. $A$ intenção novamente foi significante em todas as estimativas de preços.

\subsection{A Maldição do Vencedor}

O gráfico 2 demonstra os preços dos produtos e as medianas dos lances nos leilões com informação e sem informação. Nos dois tipos de leilões, os preços ofertados são maiores que o preço referencia ${ }^{5}$ do produto, evidenciando a Maldição do Vencedor. Apenas no produto mouse, a mediana dos lances foi maior no questionário sem informação. Nos demais produtos a mediana dos lances do questionário com informação foi superior ao sem informação.

\section{Gráfico 2 - Evidências da Maldição do Vencedor}

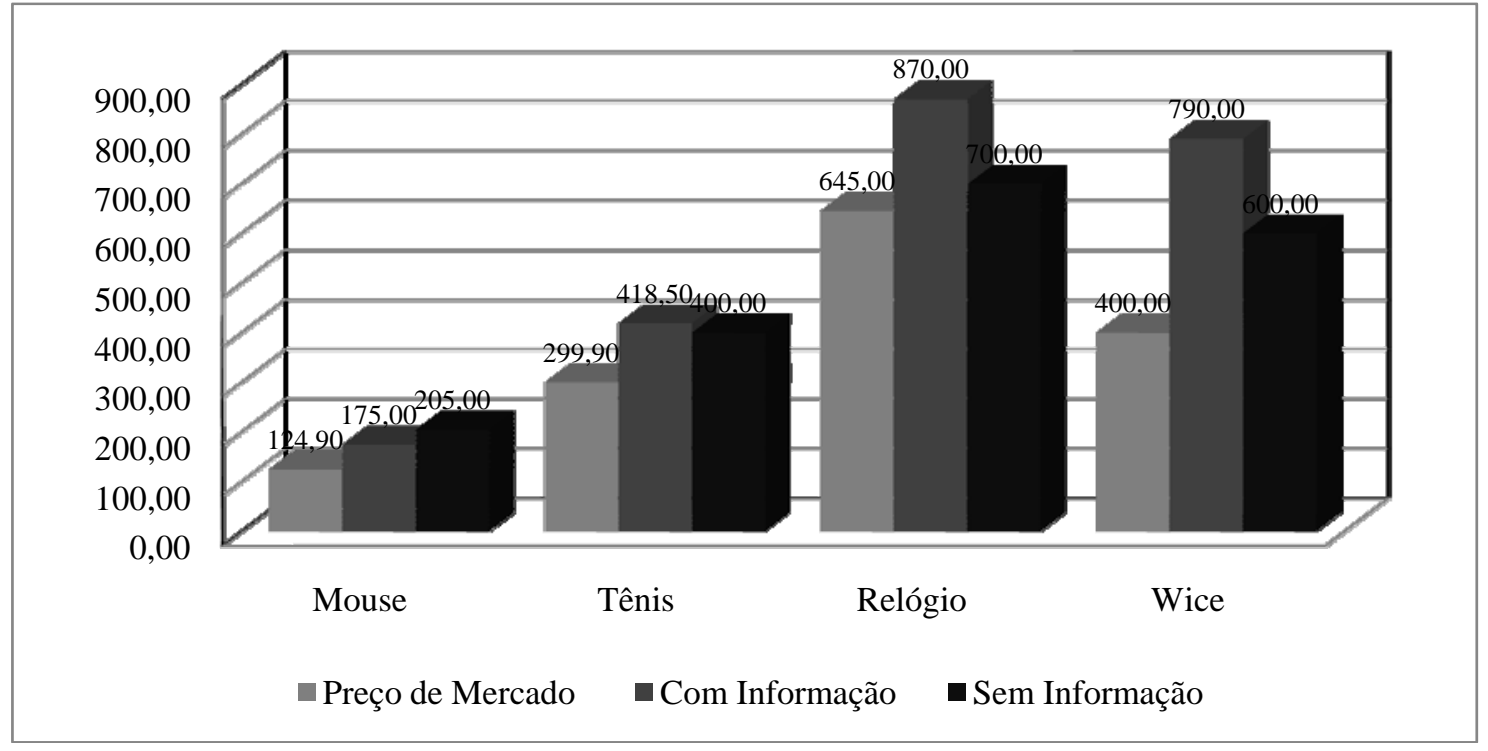

Bazerman e Samuelson (1983) avaliaram a Maldição do Vencedor, verificando a diferença entre a média dos lances vencedores é o valor real dos bem leiloados, sendo a diferença positiva concluiu-se que houve na média a maldição.

Para testar $\mathrm{H}_{2}$, foi utilizada a mediana dos lances vencedores, pois a variabilidade dos dados foi grande, enviesando a média. Desta forma, a lógica de apuração da Maldição do Vencedor foi à mesma de Bazerman e Samuelson (1983), porém foi substituída a média pela mediana. Entende-se por lances vencedores, aqueles maiores ou iguais ao valor de mercado dos produtos. Pode-se demonstrar a relação pela fórmula abaixo:

Onde:

lance vencedor do produto "p" para o participante "k"

mediana dos lances vencedores do produto " $p$ " 
Sendo o lance vencedor maior ou igual aos preços de mercado dos produtos, a mediana dos lances também será maior ou igual aos preços. A
Maldição do Vencedor será evidenciada caso a mediana de cada produto seja significativamente maior que o preço de mercado estabelecido.

Quadro 5 - Maldição do Vencedor - Cl

\begin{tabular}{|l|r|r|r|r|}
\hline Com Informação & Mouse & Tênis & Relógio & Wice \\
\hline Mediana & 175,00 & 418,50 & 870,00 & 790,00 \\
Preços & 124,90 & 299,90 & 645,00 & 400,00 \\
Variação & $40 \%$ & $40 \%$ & $35 \%$ & $98 \%$ \\
Preços $+10 \%$ & 137,39 & 329,89 & 709,50 & 440,00 \\
Variacão + 10\% & $27 \%$ & $27 \%$ & $23 \%$ & $80 \%$ \\
\hline
\end{tabular}

Quadro 6 - Maldição do Vencedor - SI

\begin{tabular}{|l|r|r|r|r|}
\hline Sem Informação & Mouse & Tênis & Relógio & Wice \\
\hline Mediana & 205,00 & 400,00 & 700,00 & 600,00 \\
Preço de mercado & 124,90 & 299,90 & 645,00 & 400,00 \\
Variação & $64 \%$ & $33 \%$ & $9 \%$ & $50 \%$ \\
Preços + 10\% & 137,39 & 329,89 & 709,50 & 440,00 \\
Variação & $49 \%$ & $21 \%$ & $-1 \%$ & $36 \%$ \\
\hline
\end{tabular}

Observa-se de acordo com os quadros 5 e 6 acima, a ocorrência da Maldição do Vencedor nos dois casos. No questionário com informação a maldição do vencedor foi maior, exceto para o produto mouse, em comparação ao sem informação. Considerando uma margem de $10 \%$ a mais sobre o preço referência a Maldição ainda continua acontecendo, exceto para o produto relógio no sem informação. Verifica-se que o efeito informação fez aumentar a Maldição do Vencedor, pois nos produtos tênis, relógio e wice, a variação foi significativamente superior que no sem informação. É interessante analisar o produto wice, que apresentou no questionário com informação a maior Maldição com quase $100 \%$ de variação em relação ao preço referência produto e no sem informação a segunda maior Maldição ficando atrás do produto mouse. Isto se deve ao desconhecimento deste produto no mercado, como aumenta a incerteza, a maior probabilidade de acontecer a superestimação dos valores.

Um dos possíveis fatores que podem explicar a subavaliação nos questionários sem informação e a superavaliação nos questionários sem informação se comparados é o efeito da seleção adversa.
Como no segundo caso os participantes tinham apenas as imagens dos produtos sem nenhuma informação eles subavaliavam os produtos para diminuir o risco inerente a estimação de preços.

\subsection{Testes de média}

Para averiguar $\mathrm{H}_{3}$, foi feito o teste entre as médias dos dois questionários, o objetivo é averiguar se elas são estatisticamente diferentes. Como a estatística descritiva já demonstrou que há diferença importante entre elas, e que em todos os casos a média dos produtos com informação é maior do que os sem informação, foi feito o teste unicaudal, onde se testou se as médias são estatisticamente iguais $\left(\mathrm{H}_{0}\right)$ ou se a média dos questionários com informação é estatisticamente maior que os sem informação, abaixo as hipóteses nula e alternativa:

$$
\begin{aligned}
& H_{0}: \bar{x}_{c i}=\bar{x}_{s i} \\
& H_{1}: \bar{x}_{c i}>\bar{x}_{s i}
\end{aligned}
$$


Quadro 7: Teste t para médias

\begin{tabular}{|l|r|r|r|r|}
\hline Teste t & Mouse & \multicolumn{1}{c|}{ Tênis } & Relógio & Wice \\
\hline Tcalculado & 3,839 & 8,064 & 5,968 & 4,360 \\
Tcrítico 1\% & 2,367 & 2,367 & 2,367 & 2,367 \\
Tcrítico 5\% & 1,661 & 1,661 & 1,661 & 1,661 \\
Tcrítico 10\% & 1,291 & 1,291 & 1,291 & 1,291 \\
\hline
\end{tabular}

Como se pode averiguar no quadro 7 acima, as estatísticas calculadas são maiores nos quatro casos, aos níveis de significância de 1\%, 5\% e $10 \%$, desta forma rejeita-se $\mathrm{H}_{0}$ nos três níveis de significância testados, ou seja, a média dos preços ofertados nos produtos com informações é maior nas quatro mercadorias testadas. Pode-se inferir que, 0 efeito informacional fez com que se elevassem os preços dos produtos.

\section{Conclusões}

Com relação a $\mathrm{H}_{1}$, (há correlação positiva entre a âncora aleatória de preços e as estimativas de valores) os testes indicaram que a relação entre a âncora aleatória e os preços ofertados é robusta para os questionários sem informação, pois em $100 \%$ dos produtos a âncora foi significante, já nos questionários com informação, a relação foi somente em $50 \%$ dos produtos e nos testes, de forma geral, o índice foi de 75\%. Desta forma, neste quesito, os resultados deste artigo convergem com o de Ariely (2008), onde foi encontrado o efeito da âncora aleatória nos produtos leiloados.

Testando $\mathrm{H}_{2}$ (o aumento do nível informacional nos leilões diminuiu a Maldição do Vencedor), observou-se que o aumento do nível informacional, em três dos quatro produtos leiloados, ao invés de diminuir, aumentou a Maldição do Vencedor. Além disso, foi averiguado que tanto nos questionários com informação quanto nos sem informação a Maldição ocorreu, nos primeiros com maior intensidade.

Para a hipótese $\mathrm{H}_{3}$, (a média dos lances nos leilões com informação é maior do que a do leilão sem informação), foi feito o teste de média, e foi encontrado que a média do leilão com informação é estatisticamente maior que média dos lances do leilão sem informação. Isto demonstra que o efeito informação aumentou as estimativas dos participantes, e no caso contrário, houve o problema de seleção adversa, que ocorre quando em função da falta de informação as pessoas subavaliam os produtos na tentativa de diminuir uma possível perda, no caso dos leilões, interpretando a falta de informação como sendo negativa.

\section{Notas}

1. Variável Dummy: Masculino 1 e Feminino 0.

2. Variável Dummy: Casado 1 e Solteiro 0. Foram desconsideradas as demais opções.

3. Variável Dummy: Brasília 1 e Natal 0.

4. Os testes de regressão estão no Apêndice do trabalho.

5. Busca feita no sítio www.bondfaro.com.br.

\section{Referências}

ARIELY, D. Previsivelmente irracional. Rio de Janeiro: Elsevier, 2008.

BAZERMAN, M. H.; SAMUELSON, W. F. I won the auction but don't want the prize. Journal of Conflict Resolution, v. 27, n. 4, p. 618-634, 1983.

BRASIL, E. Y. R.; POSTALI, F, A, S; MADEIRA, G de A. Assimetrias entre competidores nos leilões de petróleo no Brasil. In: ENCONTRO NACIONAL DE ECONOMIA, 36., 2008, Salvador. Anais... Rio de Janeiro: ANPEC, 2008.

MATTOS, C. Licitações da ANP, Petrobrás e a "maldição do vencedor". In: SALGADO, L. H.; MOTTA, R. S. da. Marcos regulatórios no Brasil: incentivos ao investimento e governança regulatória. Rio de Janeiro: IPEA, 2008.

SILVA, C. A. T. Vitória de Pirro. 2007. Disponível em:

$<$ http://financascomportamentais.blogspot.com/200 7/01/vitria-de-pirro.html\#links>. Acesso em: 13 jun. 2009.

VANZAN, D. M. O fenômeno da maldição do vencedor em leilões: um estudo experimental. 2004. 88 f. Dissertação (Mestrado em Administração) - Universidade Federal do Rio de Janeiro, Rio de Janeiro, 2004.

VARIAN, H. R. Microeconomia: princípios básicos Rio de Janeiro: Campus, 2006. 
Apêndices

Apêndice 1 - Resultados dos testes de regressão linear sem separação entre com e sem informação

\begin{tabular}{|c|c|c|c|c|c|c|}
\hline \multirow[b]{2}{*}{ Mode } & & \multicolumn{2}{|c|}{$\begin{array}{l}\text { Unstandardized } \\
\text { Coefficients }\end{array}$} & \multirow{2}{*}{$\begin{array}{c}\text { Standardized } \\
\text { Coefficients } \\
\text { Beta }\end{array}$} & \multirow[b]{2}{*}{$t$} & \multirow[b]{2}{*}{ Sig. } \\
\hline & & B & Std. Error & & & \\
\hline \multirow[t]{2}{*}{1} & (Constant) & 50.983 & 5.386 & & 9.466 & .000 \\
\hline & Dmaior & 126.351 & 13.457 & .549 & 9.389 & .000 \\
\hline \multirow[t]{3}{*}{2} & (Constant) & 45.218 & 5.469 & & 8.267 & .000 \\
\hline & Dmaior & 126.782 & 13.074 & .551 & 9.697 & .000 \\
\hline & I_Mouse & 58.666 & 16.197 & .206 & 3.622 & .000 \\
\hline \multirow[t]{4}{*}{3} & (Constant) & 52.247 & 5.926 & & 8.817 & .000 \\
\hline & Dmaior & 119.468 & 13.113 & .519 & 9.110 & .000 \\
\hline & I_Mouse & 61.801 & 15.964 & .217 & 3.871 & .000 \\
\hline & Dmenor & -36.265 & 12.838 & -.161 & -2.825 & .005 \\
\hline \multirow[t]{5}{*}{4} & (Constant) & 60.442 & 7.858 & & 7.692 & .000 \\
\hline & Dmaior & 118.485 & 13.080 & .515 & 9.059 & .000 \\
\hline & I_Mouse & 61.985 & 15.906 & .218 & 3.897 & .000 \\
\hline & Dmenor & -36.392 & 12.791 & -.162 & -2.845 & .005 \\
\hline & Sexo & -14.911 & 9.435 & -.088 & -1.580 & .116 \\
\hline
\end{tabular}

a. Dependent Variable: Mouse

Coefficients $^{\mathrm{a}}$

\begin{tabular}{|c|c|c|c|c|c|c|}
\hline \multirow[b]{2}{*}{ Mode } & & \multicolumn{2}{|c|}{$\begin{array}{c}\text { Unstandardized } \\
\text { Coefficients }\end{array}$} & \multirow{2}{*}{$\begin{array}{c}\text { Standardized } \\
\text { Coefficients } \\
\text { Beta }\end{array}$} & \multirow[b]{2}{*}{$t$} & \multirow[b]{2}{*}{ Sig. } \\
\hline & & B & Std. Error & & & \\
\hline \multirow[t]{2}{*}{1} & (Constant) & 259.090 & 11.839 & & 21.885 & .000 \\
\hline & Dmaior & 245.607 & 29.579 & .503 & 8.303 & .000 \\
\hline \multirow[t]{3}{*}{2} & (Constant) & 297.089 & 11.892 & & 24.982 & .000 \\
\hline & Dmaior & 207.608 & 27.070 & .425 & 7.669 & .000 \\
\hline & Dmenor & -187.820 & 26.439 & -.394 & -7.104 & .000 \\
\hline \multirow[t]{4}{*}{3} & (Constant) & 268.647 & 13.282 & & 20.227 & .000 \\
\hline & Dmaior & 200.622 & 26.075 & .411 & 7.694 & .000 \\
\hline & Dmenor & -180.852 & 25.469 & -.379 & -7.101 & .000 \\
\hline & I_Tenis & 83.511 & 19.856 & .221 & 4.206 & .000 \\
\hline \multirow[t]{5}{*}{4} & (Constant) & 123.115 & 23.158 & & 5.316 & .000 \\
\hline & Dmaior & 173.983 & 23.516 & .356 & 7.398 & .000 \\
\hline & Dmenor & -156.205 & 22.941 & -.327 & -6.809 & .000 \\
\hline & I_Tenis & 159.838 & 20.542 & .422 & 7.781 & .000 \\
\hline & Identidade & .254 & .035 & .400 & 7.311 & .000 \\
\hline \multirow[t]{6}{*}{5} & (Constant) & 103.175 & 24.127 & & 4.276 & .000 \\
\hline & Dmaior & 153.760 & 24.498 & .315 & 6.276 & .000 \\
\hline & Dmenor & -139.158 & 23.584 & -.292 & -5.901 & .000 \\
\hline & I_Tenis & 153.944 & 20.392 & .407 & 7.549 & .000 \\
\hline & Identidade & .255 & .034 & .401 & 7.433 & .000 \\
\hline & Informacao & 48.098 & 18.740 & .134 & 2.567 & .011 \\
\hline \multirow[t]{7}{*}{6} & (Constant) & 52.560 & 42.362 & & 1.241 & .216 \\
\hline & Dmaior & 151.496 & 24.480 & .310 & 6.189 & .000 \\
\hline & Dmenor & -136.016 & 23.618 & -.285 & -5.759 & .000 \\
\hline & I_Tenis & 155.183 & 20.354 & .410 & 7.624 & .000 \\
\hline & Identidade & .258 & .034 & .405 & 7.523 & .000 \\
\hline & Informacao & 54.914 & 19.269 & .153 & 2.850 & .005 \\
\hline & Idade & 1.718 & 1.184 & .069 & 1.452 & .148 \\
\hline
\end{tabular}

a. Dependent Variable: Tenis 
Cont. Apêndice 1 - Resultados dos testes de regressão linear sem separação entre com e sem informação

Coefficients $^{a}$

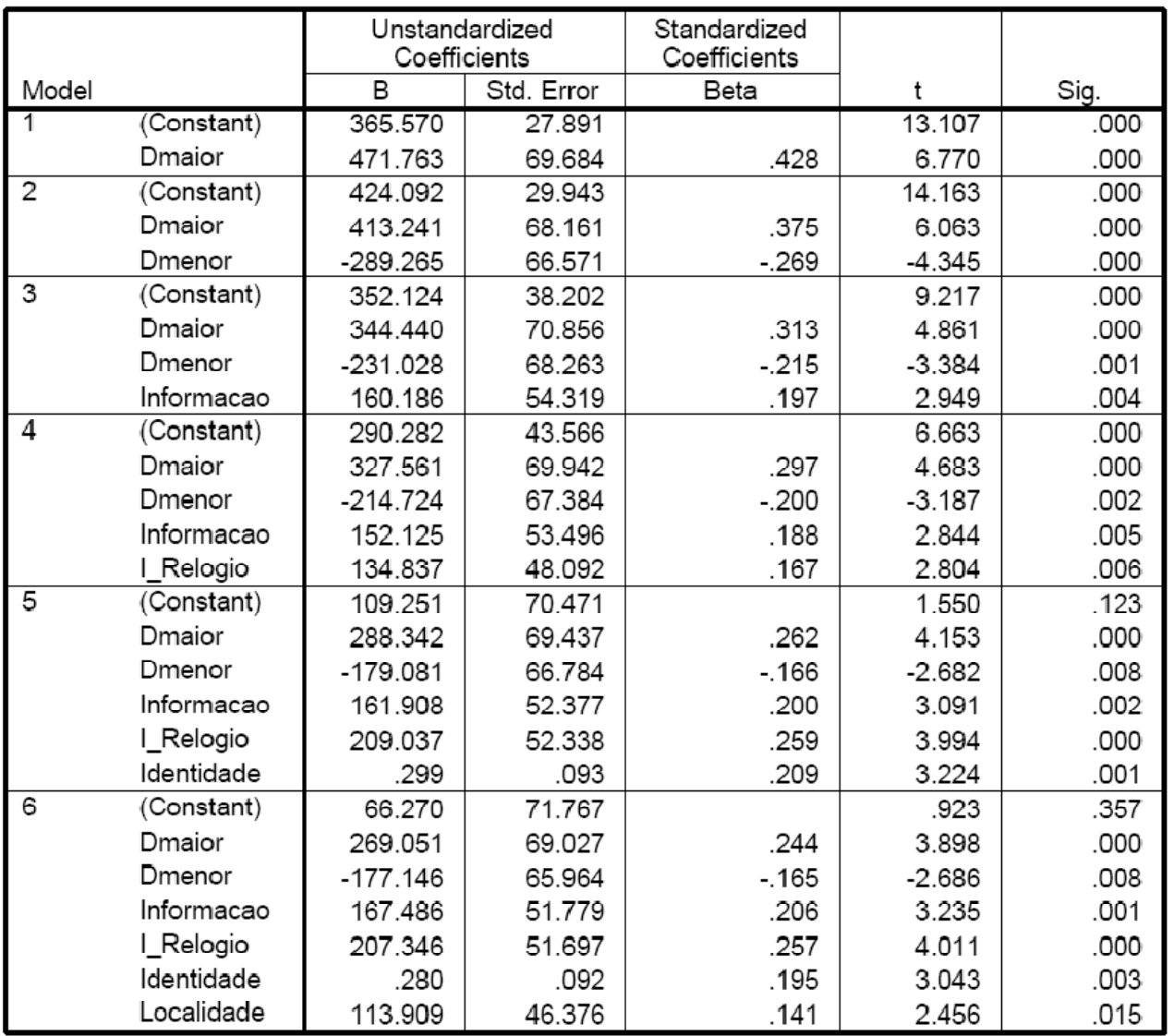

a. Dependent Variable: Relogio

Coefficients $^{a}$

\begin{tabular}{|c|c|c|c|c|c|c|}
\hline \multirow{2}{*}{\multicolumn{2}{|c|}{ Model }} & \multicolumn{2}{|c|}{$\begin{array}{l}\text { Unstandardized } \\
\text { Coefficients }\end{array}$} & \multirow{2}{*}{$\begin{array}{c}\text { Standardized } \\
\text { Coefficients } \\
\text { Beta }\end{array}$} & \multirow[b]{2}{*}{$t$} & \multirow[b]{2}{*}{ Sig. } \\
\hline & & $B$ & Std. Error & & & \\
\hline \multirow[t]{2}{*}{1} & (Constant) & 115.559 & 16.544 & & 6.985 & .000 \\
\hline & I_Wice & 316.311 & 41.977 & .467 & 7.535 & .000 \\
\hline \multirow[t]{3}{*}{2} & (Constant) & 91.228 & 16.786 & & 5.435 & .000 \\
\hline & I_Wice & 291.029 & 40.618 & .429 & 7.165 & .000 \\
\hline & Dmaiar & 176.401 & 40.113 & .263 & 4.398 & .000 \\
\hline \multirow[t]{4}{*}{3} & (Constant) & 57.564 & 20.031 & & 2.874 & .004 \\
\hline & I_Wice & 286.030 & 39.902 & .422 & 7.168 & .000 \\
\hline & Dmaior & 131.136 & 42.247 & .196 & 3.104 & .002 \\
\hline & Informacao & 91.367 & 30.926 & .185 & 2.954 & .004 \\
\hline \multirow[t]{5}{*}{4} & (Constant) & -10.395 & 33.642 & & -.309 & .758 \\
\hline & I_Wice & 325.147 & 42.395 & .480 & 7.669 & .000 \\
\hline & Dmaior & 111.678 & 42.431 & .167 & 2.632 & .009 \\
\hline & Informacao & 93.750 & 30.548 & .190 & 3.069 & .002 \\
\hline & Identidade & .136 & .054 & .156 & 2.497 & .013 \\
\hline \multirow[t]{6}{*}{5} & (Constant) & 109.361 & 66.652 & & 1.641 & .102 \\
\hline & I_Wice & 321.164 & 42.094 & .474 & 7.630 & .000 \\
\hline & Dmaior & 118.078 & 42.199 & .176 & 2.798 & .006 \\
\hline & Informacao & 78.657 & 31.160 & .160 & 2.524 & .012 \\
\hline & Identidade & .131 & .054 & .150 & 2.421 & .016 \\
\hline & Idade & -4.178 & 2.013 & -.122 & -2.076 & .039 \\
\hline
\end{tabular}

a. Dependent Variable: Wice 
Apêndice 2 - Resultados das regressões lineares: questionários sem informação

\begin{tabular}{|c|c|c|c|c|c|c|}
\hline \multirow[b]{2}{*}{ Mode } & & \multicolumn{2}{|c|}{$\begin{array}{l}\text { Unstandardized } \\
\text { Coefficients }\end{array}$} & \multirow{2}{*}{$\begin{array}{c}\text { Standardized } \\
\text { Coefficients } \\
\text { Beta }\end{array}$} & \multirow[b]{2}{*}{$t$} & \multirow[b]{2}{*}{ Sig. } \\
\hline & & $B$ & Std. Error & & & \\
\hline \multirow[t]{2}{*}{1} & (Constant) & 41.869 & 6.921 & & 6.049 & .000 \\
\hline & Dmaior & 92.664 & 18.912 & .423 & 4.900 & .000 \\
\hline \multirow[t]{3}{*}{2} & (Constant) & 36.537 & 7.176 & & 5.092 & .000 \\
\hline & Dmaior & 94.862 & 18.579 & .433 & 5.106 & .000 \\
\hline & I_Mouse & 47.019 & 20.458 & .195 & 2.298 & .023 \\
\hline \multirow[t]{4}{*}{3} & (Constant) & 48.433 & 9.203 & & 5.263 & .000 \\
\hline & Dmaior & 93.026 & 18.344 & .425 & 5.071 & .000 \\
\hline & I_Mouse & 47.927 & 20.180 & .199 & 2.375 & .019 \\
\hline & Localidade & -25.303 & 12.514 & -.169 & -2.022 & .046 \\
\hline \multirow[t]{5}{*}{4} & (Constant) & 22.328 & 13.974 & & 1.598 & .113 \\
\hline & Dmaior & 84.960 & 18.238 & .388 & 4.658 & .000 \\
\hline & I_Mouse & 70.689 & 21.822 & .293 & 3.239 & .002 \\
\hline & Localidade & -31.625 & 12.507 & -.212 & -2.529 & .013 \\
\hline & Identidade & .059 & .024 & .228 & 2.442 & .016 \\
\hline \multirow[t]{6}{*}{5} & (Constant) & 28.539 & 14.399 & & 1.982 & .050 \\
\hline & Dmaior & 81.336 & 18.244 & .372 & 4.458 & .000 \\
\hline & I_Mouse & 75.143 & 21.839 & .312 & 3.441 & .001 \\
\hline & Localidade & -31.292 & 12.417 & -.209 & -2.520 & .013 \\
\hline & Identidade & .054 & .024 & .208 & 2.230 & .028 \\
\hline & Dmenor & -29.744 & 18.495 & -.136 & -1.608 & .111 \\
\hline
\end{tabular}

a. Dependent Variable: Mouse

\begin{tabular}{|c|c|c|c|c|c|c|}
\hline \multirow[b]{2}{*}{ Mode } & & \multicolumn{2}{|c|}{$\begin{array}{l}\text { Unstandardized } \\
\text { Coefficients }\end{array}$} & \multirow{2}{*}{$\begin{array}{c}\text { Standardized } \\
\text { Coefficients } \\
\text { Beta }\end{array}$} & \multirow[b]{2}{*}{$t$} & \multirow[b]{2}{*}{ Sig. } \\
\hline & & B & Std. Error & & & \\
\hline \multirow[t]{2}{*}{1} & (Constant) & 201.817 & 13.592 & & 14.848 & .000 \\
\hline & Dmaior & 209.516 & 37.141 & .474 & 5.641 & .000 \\
\hline \multirow[t]{3}{*}{2} & (Constant) & 222.271 & 13.990 & & 15.887 & .000 \\
\hline & Dmaior & 189.062 & 35.577 & .427 & 5.314 & .000 \\
\hline & Dmenor & -132.271 & 35.577 & -.299 & -3.718 & .000 \\
\hline \multirow[t]{4}{*}{3} & (Constant) & 200.604 & 14.968 & & 13.402 & .000 \\
\hline & Dmaior & 182.527 & 34.162 & .413 & 5.343 & .000 \\
\hline & Dmenor & -133.166 & 34.104 & -.301 & -3.905 & .000 \\
\hline & I_Tenis & 84.605 & 25.957 & .249 & 3.259 & .001 \\
\hline \multirow[t]{5}{*}{4} & (Constant) & 98.512 & 29.931 & & 3.291 & .001 \\
\hline & Dmaior & 155.767 & 32.886 & .352 & 4.737 & .000 \\
\hline & Dmenor & -103.741 & 32.985 & -.235 & -3.145 & .002 \\
\hline & I_Tenis & 147.796 & 29.392 & .434 & 5.028 & .000 \\
\hline & Identidade & .181 & .047 & .345 & 3.866 & .000 \\
\hline
\end{tabular}

a. Dependent Variable: Tenis 
Cont. Apêndice 2 - Resultados das regressões lineares: questionários sem informação

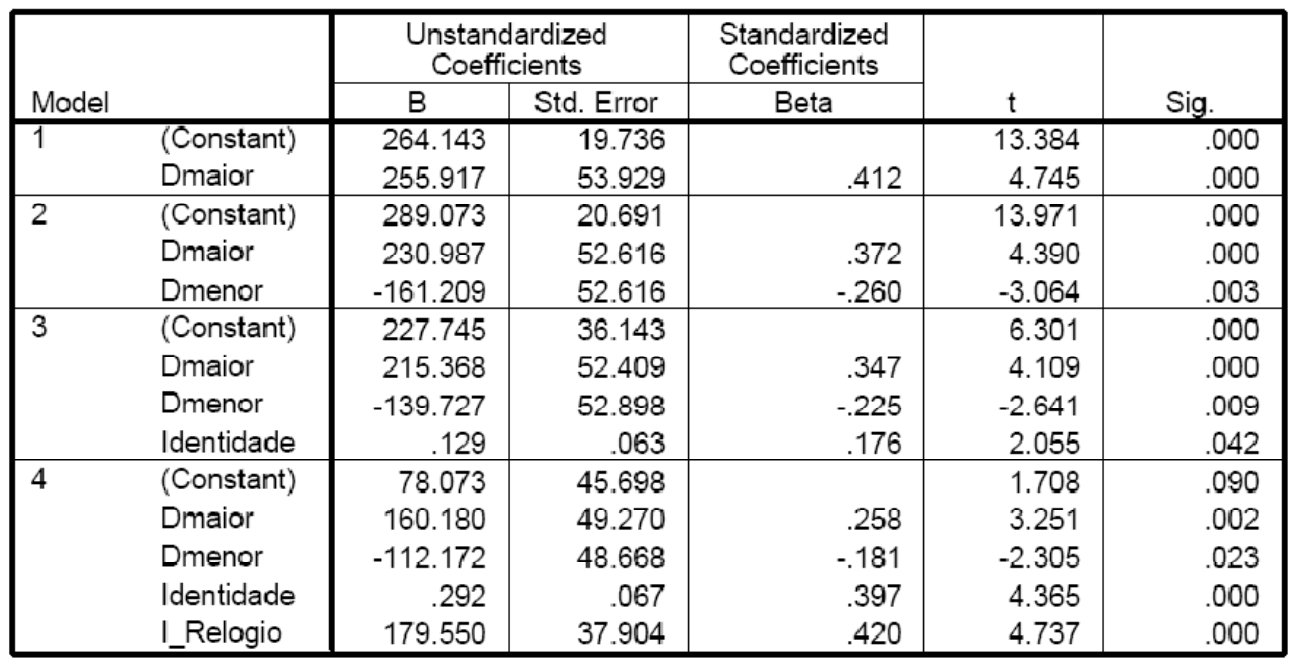

a. Dependent Variable: Relogio

\begin{tabular}{|c|c|c|c|c|c|c|}
\hline \multirow[b]{2}{*}{ Mode } & & \multicolumn{2}{|c|}{$\begin{array}{l}\text { Unstandardized } \\
\text { Coefficients }\end{array}$} & \multirow{2}{*}{$\begin{array}{c}\text { Standardized } \\
\text { Coefficients } \\
\text { Beta }\end{array}$} & \multirow[b]{2}{*}{$t$} & \multirow[b]{2}{*}{ Sig. } \\
\hline & & $B$ & Std. Error & & & \\
\hline & (Constant) & 77.908 & 9.699 & & 8.033 & .000 \\
\hline & Dmaior & 150.025 & 26.502 & .475 & 5.661 & .000 \\
\hline \multirow[t]{3}{*}{2} & (Constant) & 86.846 & 10.371 & & 8.374 & .000 \\
\hline & Dmaior & 141.087 & 26.373 & .447 & 5.350 & .000 \\
\hline & Dmenor & -57.797 & 26.373 & -.183 & -2.192 & .031 \\
\hline \multirow[t]{4}{*}{3} & (Constant) & 75.583 & 9.872 & & 7.656 & .000 \\
\hline & Dmaior & 113.870 & 25.028 & .361 & 4.550 & .000 \\
\hline & Dmenor & -54.230 & 24.306 & -.172 & -2.231 & .028 \\
\hline & I_Wice & 115.441 & 25.525 & .355 & 4.523 & .000 \\
\hline \multirow[t]{5}{*}{4} & (Constant) & 46.013 & 19.301 & & 2.384 & .019 \\
\hline & Dmaior & 101.676 & 25.714 & .322 & 3.954 & .000 \\
\hline & Dmenor & -43.944 & 24.754 & -.139 & -1.775 & .079 \\
\hline & I_Wice & 137.548 & 28.171 & .423 & 4.883 & .000 \\
\hline & Identidade & .058 & .032 & .154 & 1.777 & .078 \\
\hline
\end{tabular}

a. Dependent Variable: Wice 
Apêndice 3 - Resultados das regressões lineares: questionários com informação

\begin{tabular}{|c|c|c|c|c|c|c|}
\hline \multirow[b]{2}{*}{ Mode } & & \multicolumn{2}{|c|}{$\begin{array}{l}\text { Unstandardized } \\
\text { Coefficients }\end{array}$} & \multirow{2}{*}{$\begin{array}{c}\begin{array}{c}\text { Standardized } \\
\text { Coefficients }\end{array} \\
\text { Beta }\end{array}$} & \multirow[b]{2}{*}{$\mathrm{t}$} & \multirow[b]{2}{*}{ Sig. } \\
\hline & & B & Std. Error & & & \\
\hline \multirow[t]{2}{*}{1} & (Constant) & 78.467 & 8.935 & & 8.782 & .000 \\
\hline & Dmaior & 135.199 & 28.876 & 439 & 4.682 & .000 \\
\hline \multirow[t]{3}{*}{2} & (Constant) & 56.675 & 11.230 & & 5.047 & .000 \\
\hline & Dmaior & 118.053 & 28.277 & .383 & 4.175 & .000 \\
\hline & Localidade & 50.064 & 16.675 & .275 & 3.002 & .003 \\
\hline \multirow[t]{4}{*}{3} & (Constant) & 48.047 & 11.068 & & 4.341 & .000 \\
\hline & Dmaior & 114.426 & 27.019 & .371 & 4.235 & .000 \\
\hline & Localidade & 53.287 & 15.951 & .293 & 3.341 & .001 \\
\hline & I_Mouse & 87.729 & 27.949 & .270 & 3.139 & .002 \\
\hline \multirow[t]{5}{*}{4} & (Constant) & 55.350 & 11.954 & & 4.630 & .000 \\
\hline & Dmaior & 110.708 & 26.920 & .359 & 4.112 & .000 \\
\hline & Localidade & 49.449 & 16.023 & .272 & 3.086 & .003 \\
\hline & I_Mouse & 82.330 & 27.954 & .253 & 2.945 & .004 \\
\hline & Dmenor & -36.747 & 23.753 & -.135 & -1.547 & .125 \\
\hline
\end{tabular}

a. Dependent Variable: Mouse

\begin{tabular}{|c|c|c|c|c|c|c|}
\hline \multirow[b]{2}{*}{ Mode } & & \multicolumn{2}{|c|}{$\begin{array}{l}\text { Unstandardized } \\
\text { Coefficients }\end{array}$} & \multirow{2}{*}{$\begin{array}{l}\text { Standardized } \\
\text { Coefficients } \\
\text { Beta }\end{array}$} & \multirow[b]{2}{*}{$t$} & \multirow[b]{2}{*}{ Sig. } \\
\hline & & $B$ & Std. Error & & & \\
\hline \multirow[t]{2}{*}{1} & (Constant) & 406.767 & 18.084 & & 22.493 & .000 \\
\hline & Dmenor & -208.725 & 50.613 & -.395 & -4.124 & .000 \\
\hline \multirow[t]{3}{*}{2} & (Constant) & 305.051 & 33.864 & & 9.008 & .000 \\
\hline & Dmenor & -175.742 & 48.742 & -.333 & -3.606 & .001 \\
\hline & Identidade & .207 & .059 & .321 & 3.479 & .001 \\
\hline \multirow[t]{4}{*}{3} & (Constant) & 171.989 & 42.267 & & 4.069 & .000 \\
\hline & Dmenor & -138.193 & 44.902 & -.262 & -3.078 & .003 \\
\hline & Identidade & .341 & .061 & .529 & 5.562 & .000 \\
\hline & I_Tenis & 152.680 & 33.370 & .428 & 4.575 & .000 \\
\hline \multirow[t]{5}{*}{4} & (Constant) & 44.677 & 68.643 & & .651 & .517 \\
\hline & Dmenor & -129.075 & 44.022 & -.244 & -2.932 & .004 \\
\hline & Identidade & .355 & .060 & .550 & 5.896 & .000 \\
\hline & I_Tenis & 157.314 & 32.647 & .441 & 4.819 & .000 \\
\hline & İade & 4.753 & 2.048 & .187 & 2.321 & .023 \\
\hline \multirow[t]{6}{*}{5} & (Constant) & 59.626 & 68.596 & & .869 & .387 \\
\hline & Dmenor & -124.645 & 43.688 & -.236 & -2.853 & .005 \\
\hline & Identidade & .338 & .060 & .524 & 5.588 & .000 \\
\hline & I_Tenis & 145.537 & 33.119 & .408 & 4.394 & .000 \\
\hline & Idade & 4.336 & 2.044 & .171 & 2.121 & .037 \\
\hline & Dmaior & 81.368 & 49.424 & .136 & 1.646 & .103 \\
\hline
\end{tabular}

a. Dependent Variable: Tenis 
Cont. Apêndice 3 - Resultados das regressões lineares: questionários com informação

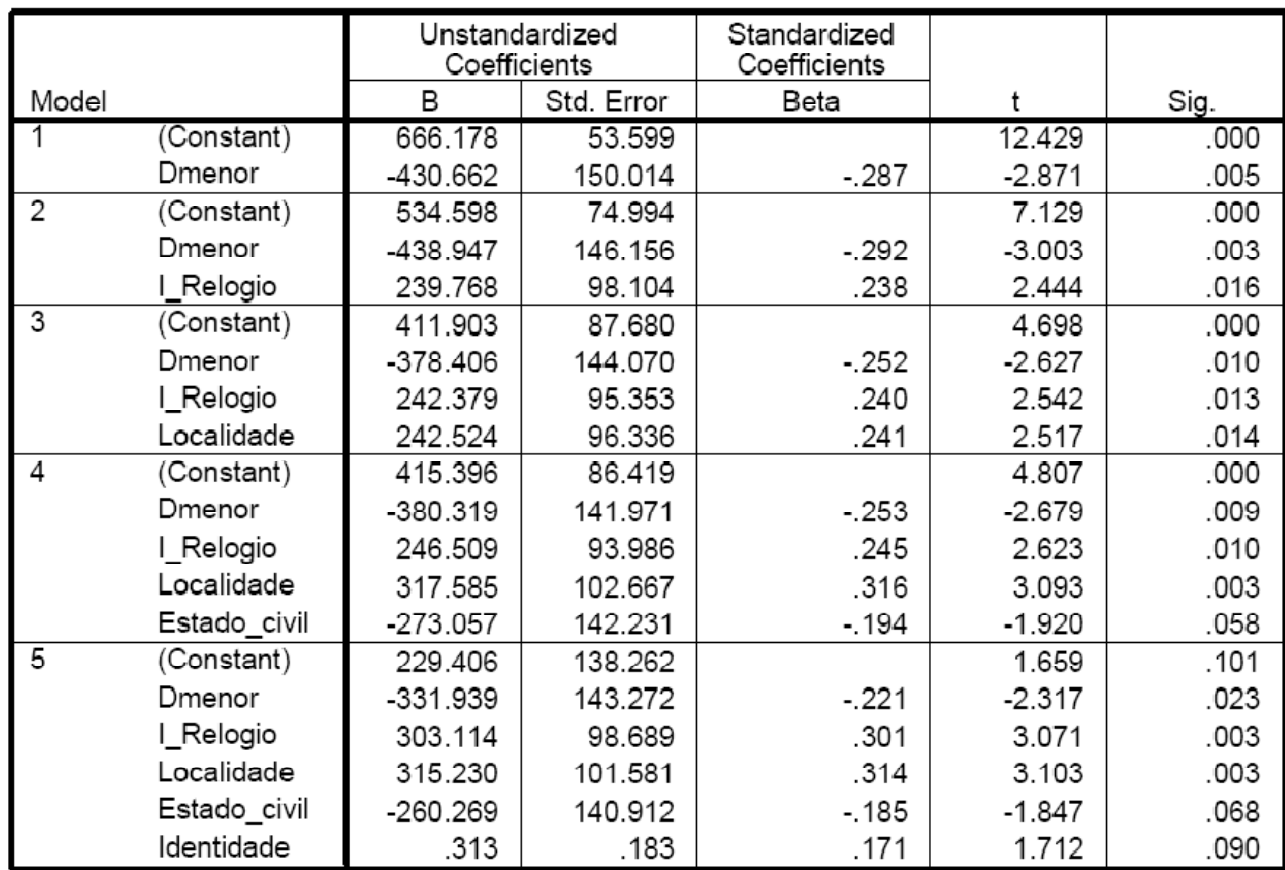

a. Dependent Variable: Relogio

\begin{tabular}{|ll|r|r|r|r|r|}
\hline \multirow{2}{*}{ Model } & \multicolumn{2}{|c|}{$\begin{array}{c}\text { Unstandardized } \\
\text { Coefficients }\end{array}$} & $\begin{array}{c}\text { Standardized } \\
\text { Coefficients }\end{array}$ & & \\
\cline { 3 - 4 } & & \multicolumn{1}{|c|}{ B } & Std. Error & \multicolumn{2}{c|}{ Beta } & \multicolumn{1}{c|}{ Sig. } \\
\hline & (Constant) & 162.113 & 32.446 & & 4.996 & .000 \\
& I_Wice & 428.463 & 74.146 & .516 & 5.779 & .000 \\
\hline & (Constant) & 149.699 & 32.146 & & 4.657 & .000 \\
& I_Wice & 375.355 & 75.962 & .452 & 4.941 & .000 \\
& Dmaior & 235.882 & 101.580 & .212 & 2.322 & .022 \\
\hline 3 & (Constant) & 358.956 & 105.337 & & 3.408 & .001 \\
& I_Wice & 364.932 & 74.774 & .440 & 4.880 & .000 \\
& Dmaior & 262.045 & 100.556 & .236 & 2.606 & .011 \\
& Idade & -8.470 & 4.068 & -.180 & -2.082 & .040 \\
\hline 4 & (Constant) & 392.323 & 105.615 & & 3.715 & .000 \\
& I_Wice & 354.789 & 74.043 & .427 & 4.792 & .000 \\
& Dmaior & 245.682 & 99.696 & .221 & 2.464 & .016 \\
& Idade & -8.889 & 4.023 & -.189 & -2.210 & .030 \\
& Dmenor & -152.534 & 83.831 & -.156 & -1.820 & .072 \\
\hline
\end{tabular}

a. Dependent Variable: Wice 


\section{Apêndice 4 - Questionário sem Informação}

Regras:

\section{QUESTIONÁRIO}

- coloque os três últimos números de sua identidade dentro do quadro ao lado de cada produto;

- veja os quatro produtos e, responda às duas perguntas ao lado de cada produto;

- O que der o lance mais próximo do valor de mercado do produto, receberá uma caixa de chocolate.
1.1. Idade $-(\quad)$
1.2 Gênero ( ) masculino ( ) feminino
1.3 Estado Civil: ( ) Casado(a) ( ) Solteiro (a) ( ) divorciado (a) ( ) outros

1.4 Nome:

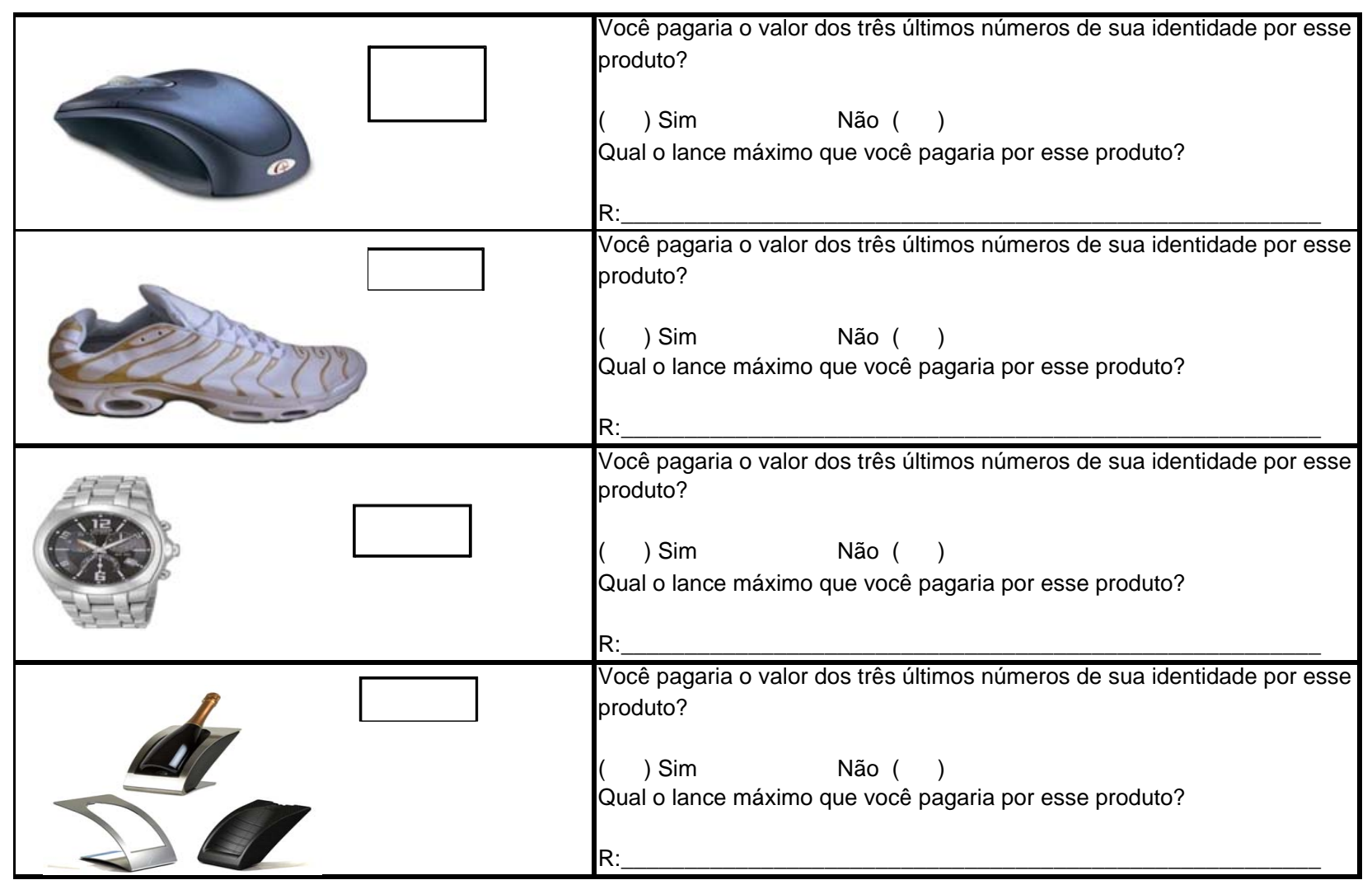




\section{Apêndice 5 - Questionário com Informação}

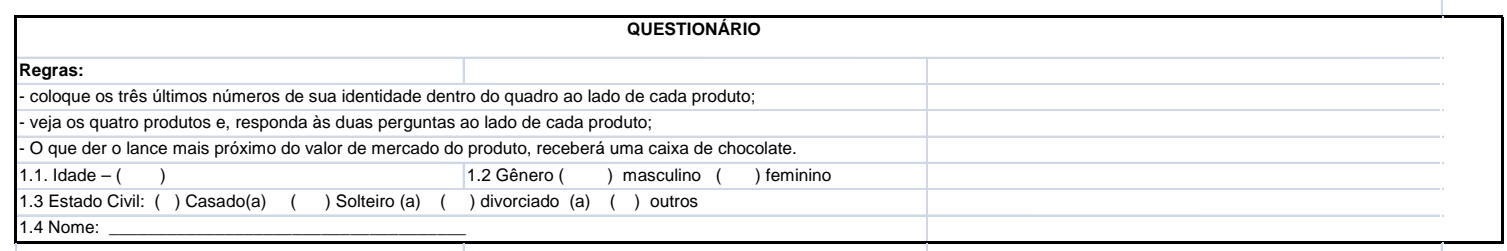

\begin{tabular}{|c|c|c|}
\hline 45 & 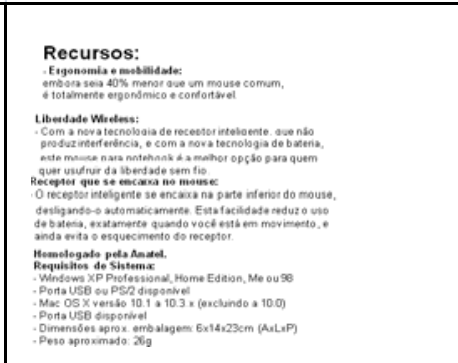 & $\begin{array}{l}\text { Você pagaria o valor dos três últimos números de sua } \\
\text { identidade por esse produto? } \\
\text { ( ) Sim Não ( ) } \\
\text { Qual o lance máximo que você pagaria por esse produto? } \\
\text { R: }\end{array}$ \\
\hline & $\begin{array}{l}\text { Air Max TN - Branco e } \\
\text { Dourado Degradé } \\
\text { Codigo: } 1521 \\
\text { Descriçăo } \\
\text { Para a pessoa que procura } \\
\text { amortecimento e durabilidade. } \\
\text { Cabedal: } \\
\text { Em Mesh para maior leveza. } \\
\text { Entressola: } \\
\text { Em Phylon com a tecnologia Nike } \\
\text { Shox no calcanhar. } \\
\text { Sola: } \\
\text { Duralon oferecendo maior durabilidade. }\end{array}$ & $\begin{array}{l}\text { Você pagaria o valor dos três últimos números de sua } \\
\text { identidade por esse produto? } \\
\text { ( ) Sim Não ( ) } \\
\text { Qual o lance máximo que você pagaria por esse produto? } \\
\text { R: }\end{array}$ \\
\hline CITIZEN & $\begin{array}{l}\text { RELÓGIO CITIZEN CRONOGRAPH } \\
\text { ECO-DRIVE SAFIRA BL7150-57E } \\
\text { Descriçāo do Item } \\
\text { Cronógrafo } \\
\text { Calendário } \\
\text { Alarme } \\
\text { Lente em Cristal de Safira } \\
\text { Ponteiro } 24 \mathrm{~h} \\
\text { Caixa e pulseira em aço inox } \\
\text { WR } 100 \mathrm{~m}\end{array}$ & $\begin{array}{l}\text { Você pagaria o valor dos três últimos números de sua } \\
\text { identidade por esse produto? } \\
\text { ( ) Sim Não ( ) } \\
\text { Qual o lance máximo que você pagaria por esse produto? } \\
\text { R: }\end{array}$ \\
\hline & \begin{tabular}{|} 
SUPORTE PARA VINHO WICE \\
Os baldes de gelo, destinados a manter a temperatura \\
de vinhos e espumantes durante o consumo, já podem \\
ser substituídos por uma peça com sdesign simpático e \\
de função ecologicamente correta. O suporte para \\
vinhos com manutenção de temperatura Wice é um \\
produto da Itália, que começa a ser comercializado no \\
Brasil. Em diversas cores, como preto, prata e vermelho, \\
o Wice é composto de um recipiente com líquido \\
atóxico que deve ser levado ao congelador e depois \\
fixado no suporte, onde a garrafa irá descansar. Além do \\
rótulo exposto e da temperatura mantida por cerca de \\
três a quatro horas, outra vantagem da peça é não \\
desperdiçar a água utilizada na produção de gelo. Além \\
disso os materiais são $100 \%$ recicláveis.
\end{tabular} & 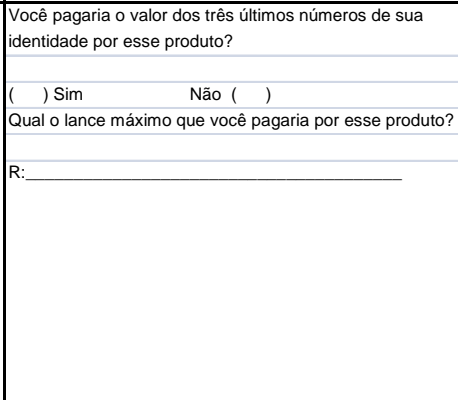 \\
\hline
\end{tabular}

